\title{
Britannin, a Sesquiterpene Lactone Induces ROS- Dependent Apoptosis in NALM-6, REH, and JURKAT Cell Lines And Produces a Synergistic Effect With Vincristine
}

\section{Hassan Mohammadlou}

Shaheed Beheshti University of Medical Sciences

Maryam Hamzeloo-Moghadam

Shaheed Beheshti University of Medical Sciences

Mohammad Hossein Mohammadi

Shaheed Beheshti University of Medical Sciences

Amir Yami

Shaheed Beheshti University of Medical Sciences

Ahmad Gharehbaghian ( $\nabla$ gharehbaghian@sbmu.ac.ir )

Shaheed Beheshti University of Medical Sciences

\section{Research Article}

Keywords: Acute Lymphoblastic Leukemia, Britannin, NALM-6 cells, ROS, Vincristine

Posted Date: April 8th, 2021

DOl: https://doi.org/10.21203/rs.3.rs-369748/v1

License: (c) (i) This work is licensed under a Creative Commons Attribution 4.0 International License.

Read Full License 


\title{
Britannin, a Sesquiterpene Lactone induces ROS-dependent apoptosis in NALM-6, REH, and JURKAT cell lines and produces a synergistic effect with Vincristine
}

\begin{abstract}
Hassan Mohammadlou ${ }^{\mathrm{a}}$, Maryam Hamzeloo-Moghadam ${ }^{\mathrm{b}}$, Mohammad Hossein Mohammadi $^{\mathrm{c}}$
\end{abstract}
Amir Yami ${ }^{\mathrm{a}}$, Ahmad Gharehbaghian ${ }^{\mathrm{a}, \mathrm{d}^{*}}$

${ }^{a}$ Department of Laboratory Hematology and Blood Bank, School of Allied Medical Sciences, Shahid Beheshti University of Medical Sciences, Tehran, Iran

${ }^{b}$ Traditional Medicine and Materia Medica Research Center and Department of Traditional Pharmacy, School of Traditional Medicine, Shahid Beheshti University of Medical Sciences, Tehran, Iran

${ }^{c}$ Laboratory Hematology and blood Banking Department School of Allied Medical Sciences, Shahid Beheshti University of Medical Sciences HSCT research center, Tehran, Iran.

${ }^{d}$ Pediatric Congenital Hematologic Disorders Research Center, School of Allied Medical Sciences, Shahid Beheshti University of Medical Sciences, Tehran, Iran

*Corresponding author: Ahmad Gharehbaghian

Department of Laboratory Hematology and Blood Bank, School of Allied Medical Sciences, Shahid Beheshti University of Medical Sciences, Tehran, Iran

E-mail: gharehbaghian@sbmu.ac.ir 


\begin{abstract}
Britannin, a Sesquiterpene Lactone isolated from Inula aucheriana, has recently gained attractions in the therapeutic fields due to its vast cytotoxic properties in different types of cancers. This study was designed to evaluate the cytotoxic effect of this agent on Acute Lymphoblastic Leukemia (ALL) cell lines, either as a monotherapy or in combination with Vincristine (VCR). The results obtained in this study showed that while Britannin reduced the viability of ALL cell lines such as NALM-6, REH, and JURKAT cells, it did not exert cytotoxicity against normal Peripheral Blood Mononuclear Cells (PBMCs) and L929 cells. Among tested cells, pre-B ALL-derived NALM-6 cells had the highest sensitivity to Britannin. Moreover, we found that Britannin induced p21/p27-mediated G1 cell cycle arrest cells and Reactive Oxygen Specious (ROS)-mediated apoptotic cell death in NALM-6 cells. When NALM-6 cells were treated with N-acetyl-L-Cysteine (NAC), a scavenger of ROS, we found that Britannin could induce neither apoptosis nor reduce the survival of the cells, suggesting that the cytotoxic effect of Britannin is induced through ROS-dependent manner. The cytotoxic effect of Britannin also was potentiated by autophagy suppression using Chloroquine (CQ). Moreover, we found that a low dose of Britannin enhanced the effect of Vincristine in NALM-6 cells by inducing apoptotic cell death via altering the expression of apoptotic-related genes. Overall, our results proposed a mechanism for the cytotoxic effect of Britannin, either as a single agent or in combination with Vincristine, in NALM-6 cells.
\end{abstract}

Keywords: Acute Lymphoblastic Leukemia; Britannin; NALM-6 cells; ROS; Vincristine 


\section{Introduction}

As the most common malignancies in pediatrics, Acute Lymphoblastic Leukemia (ALL), with an incidence rate of $25 \%$ of all childhood malignancies is a heterogeneous disease that mostly affects children and teenagers aged between 1-19 years old [1,2]. As the age increases, the prognosis of the disease shifts from a good prognosis with a cure rate of $90 \%$ to a poor prognosis with a cure rate of less than $40 \%$ [3]. According to the affected lineage, ALL could be divided into two main sub-groups; B-Cell Precursor (BCP) lineage (BCP-ALL), which is accounted for $85 \%$ of pediatric ALL, and less common T-cell precursor lineage (T-ALL) [4]. The presence of fundamental genetic abnormalities such as translocations, mutations, and deletions in different types of genes in ALL patients has made the treatment of the disease difficult. Although chemotherapy and CNS radiotherapy have improved the overall survival of the patients, especially in the children group, the intensity of these approaches would bring significant adverse effects for patients.

Moreover, despite the increase in event-free survival and the overall survival of patients (94.1\%), the risk of disease relapse is one of the most challenging issues in the treatment of ALL [5]. Currently, the only hopeful treatment strategy in the cases of relapse or severe disease cases is stem cell transplantation, which the lack of appropriate donor and procedure make it challenging for the physicians [6]. Thereby, the identification of new drugs with higher efficacy has obtained tremendous attention lately. The affords are to find a new anti-leukemic agent that, while significantly eliminating leukemic cell population and makes the team with other chemotherapy drugs, has low cytotoxicity on the normal cells. The significant anti-cancer properties of Vincristine (VCR) and Vinblastine are an alkaloid derived from Madagascar periwinkle Catharanthus roseus [7] together with the promising anti-leukemic effects obtained from Centaurea albonitens extract [8] and Ergolide [9] have attracted attention to herbal medications in the treatment of ALL.

Asteraceae plants are known for their biologically active sesquiterpene lactones. Inula aucheriana, from this family, has been recently investigated for its chemical constituents, and Britannin, a Sesquiterpene Lactone (SL), has been reported from this plant $[10,11]$. Inula genus has more than 100 species, which could be found in Europe, Asia, and Africa [12]. It has also been shown that the SL compounds of this genus have cytotoxic effects due to the presence of $\alpha$-methylene- $\gamma$-lactone [13]. It has also shown that the SL compounds of this plant have anti-cancer effects due to the presence of $\alpha$-methylene- $\gamma$-lactone [14] alongside their ability to treat infections and inflammatory diseases. Recently, the anti-cancer property of Britannin has been reported in several cancer cells $[15,16]$. In pancreatic cells, it has been indicated that Britannin induced apoptotic cell death through FOXO-dependent up-regulation of BIM [14]. Britannin also activated AMP-activated Protein 
Kinase (AMPK) and subsequently suppressed mTOR to induce cytotoxicity in liver cancer cells [17]. Despite the compelling number of studies proposing a mechanism for the cytotoxic property of Britannin, the mechanism of action of these drugs is elusive in hematologic malignancies. Therefore, we aimed to evaluate the molecular mechanisms of Britannin in ALL-derived cell lines. 


\section{Materials and methods}

\section{Isolation of Britannin}

Britannin was isolated from Inula aucheriana DC (voucher herbarium number: TMRC 3173 kept at the Herbarium of TMRC, Shahid Beheshti University of Medical Sciences). The plant material was collected from the West Azerbaijan province of Iran. Britannin was obtained by chromatographic methods, including Vacuum Liquid Chromatography and SPE. NMR spectral data were used to confirm the structure [14]. In the present study, we prepared the working solution of Britannin $(100 \mu \mathrm{M})$ through dissolving $2.8 \mathrm{mg}$ of Britannin crystal in $76.7 \mu \mathrm{L}$ of Dimethyl Sulfoxide (DMSO). Then, for treating Acute Lymphoblastic Leukemia (ALL) cell lines with this agent at the concentrations of $0-15 \mu \mathrm{M}$, we diluted the working stock several times with RPMI1640 medium.

\section{Cell culture and drug treatment}

ALL-derived NALM-6 cells, REH cells and, JURKAT cells were purchased from the Pasteur Institute (Tehran, Iran) and were cultured in RPMI1640 medium containing 10\% fetal bovine serum, $50 \mathrm{mg} / \mathrm{ml}$ Streptomycin, and $30 \mathrm{mg} / \mathrm{ml}$ Penicillin at $37^{\circ} \mathrm{C}$ in the presence of $5 \% \mathrm{CO}_{2}$ in a humidified incubator. L929 cells used as control cells were grown in a similar condition as the leukemic cell lines. After reached to the desired confluency, all cells were treated with Britannin. In addition to this agent, NALM-6 cells were being exposed to Vincristine (VCR) (Sigma, Germany), autophagy inhibitor Chloroquine (CQ) (Sigma, Germany), and N-Acetyl-L-Cysteine (NAC).

\section{MTT assay}

To evaluate the cytotoxic effect of Britannin on ALL cell lines, cells were cultured in 96-well plates and were treated with the agent up to $48 \mathrm{~h}$. NALM-6 cells were also treated with Britannin in the presence of other agents such as CQ, NAC, and VCR for further evaluation. To evaluate the metabolic activity of the cells, after the incubation time, $100 \mu \mathrm{L}$ of MTT [3-(4,5-dimethylthiazol-2-yl)-2,5-diphenyltetrazolium bromide] (Sigma, Germany) was added to each well, and the plates were kept in the incubator for $4 \mathrm{~h}$. Then, the plates were centrifuged, and the media of each well was replaced with $100 \mu \mathrm{l}$ of DMSO to dissolve the resulting formazan. After a few minutes, the absorbance of each sample was read at $570 \mathrm{~nm}$ by an ELISA reader. 


\section{Trypan blue staining}

Trypan blue was used to evaluate whether Britannin could reduce the survival of NALM-6 cells. To do so, NALM- 6 cells were treated with Britannin at concentrations of 1, 3, and $5 \mu \mathrm{M}$. After $24 \mathrm{~h}$ or $48 \mathrm{~h}$, drug-treated cells were harvested and stained by Trypan blue dye. The number of the cells was counted manually using a light microscope.

\section{Cell cycle analysis}

PI staining was used to evaluate the effect of Britannin on the progression of the cell cycle in NALM-6 cells. The number of NALM- 6 cells that we need at the primary stage of the test was $5 \times 10^{5}$.This number of the cells was exposed to the agent for $48 \mathrm{~h}$ and then were harvested using centrifugation. The harvested cells were washed twice with PBS so that there were not any remained media. The cell pellets were fixed with ethanol (70\%) overnight. $1 \mathrm{ml}$ of PI MASTER MIX solution containing $40 \mu \mathrm{L}, 10 \mu \mathrm{L}$ RNase, and $950 \mu \mathrm{L}$ PBS was added to the cells. After $30 \mathrm{~min}$, the distribution pattern of the cells was examined using flow cytometry.

\section{Annexin-V/PI staining assay}

Flow cytometry and Annexin V-FITC staining were performed to examine the effect of Britannin, CQ, and VCR, either alone or in combination, on NALM- 6 cells. For this analysis, we needed $5 \times 10^{5}$ NALM- 6 cells at the primary stage. After exposing the cells to the agents, cells were collected, washed and, stained with Annexin VFITC and PI $(5 \mu \mathrm{L})$. After remaining for 15 min at dark, BD FACS Calibur (BD biosciences, SanJose, CA, USA) was used to analyze the amount of Phosphatidylserine (PS) externalization on the surface of NALM-6 cells. Flowjo 7.6 software was used for data analysis.

\section{Acridine orange dye method}

To investigate whether treatment of NALM-6 cells with Britannin is coupled with the induction of autophagy, drug-treated cells were stained with $10 \mu \mathrm{g} / \mathrm{ml}$ of Acridine orange dye. The samples were placed on slides, and the induction of autophagy was evaluated using a fluorescent microscope.

\section{Hoechst33258 staining}

To determine whether induction of cell death due to Britannin was due to the induction of apoptotic cell death, we used Hoechst33258 staining and a fluorescent microscope. For this staining, $5 \times 10^{5}$ of drug-treated NALM-6 cells were exposed to $1 \mu 1$ Hoechst33258 dye. Then, $10 \mu$ of the suspension was placed on a slide, and the staining pattern of the nucleus was analyzed using a fluorescent microscope. The nucleus of the cells which 
underwent apoptosis appears as irregular blue fragments; however, the nucleus of the normal cells absorb the dye uniformly.

\section{RNA extraction, cDNA synthesis and, RT-PCR analysis}

Britannin-treated cells were exposed to Trizol reagent for RNA extraction and to TAKARA kit (Japan) for cDNA synthesis. Real-time PCR was performed using SYBR Green PCR. ABL was the housekeeping gene in the present study. The primers used to evaluate the expression of genes are shown in Table 1.

\section{Determination of combination index (CI) and dose reduction index (DRI)}

To investigate the efficacy of drug combinations, the reduction of cell survival was examined, and the combination index (CI) was evaluated as described previously [18]. CI values of $<1,=1$, and $>1$ indicate synergism, additive effect, and antagonism of drugs, respectively (Table 2).

\section{Intracellular ROS measurement}

For evaluating the effect of Britannin on the production of ROS in NALM-6 cells, we need the primary number of $5 \times 10^{5}$. Cells were treated with different concentrations of the agent and then, after $48 \mathrm{~h}$, were subjected to fluorescent Reactive Oxygen Species (ROS) detection kit, which was obtained from Invitrogen detection Technologies (Eugene, Oregon, USA). Flowjo 7.6 software was used for data analysis.

\section{Statistical Analysis}

One-way ANOVA and post hoc Tukey multiple comparisons were used for data analysis. All analyses were performed using SPSS software version 22. A $P$-value of $<0.05$ was considered to be statistically significant. 


\section{Results}

\section{The cytotoxic effect of Britannin on Acute Lymphoblastic Leukemia (ALL) cell lines}

To evaluate the effect of Britannin on the viability of ALL cell lines, NALM-6, REH (pre-B ALL cells), and JURKAT (T-ALL cells) were treated with different concentrations of the agent. The results of the MTT assay showed that $48 \mathrm{~h}$ treatment with Britannin resulted in a reduction of cell viability in all tested cell line and NALM-6 cells had the lowest IC50 value $(3.2 \mu \mathrm{M})$ as compared to REH with the IC50 value of $3.4 \mu \mathrm{M}$ and JURKAT with IC50 of $6.1 \mu \mathrm{M}$ (Fig.1a). In order to investigate whether Britannin has a cytotoxic effect in ALL cells and could induce cell death, we chose the most sensitive cell line (NALM-6) for further analysis. NALM-6 cells were treated with increasing concentrations of Britannin (1-5 $\mu \mathrm{M})$ for 24 and $48 \mathrm{~h}$. MTT and Trypan blue assays showed that the survival rates of NALM-6 cells reduced in a dose- and time-dependent manner (Fig. 1b). Also, results showed that Britannin at the concentration of $3 \mu \mathrm{M}$ had no cytotoxic effect on either normal PBMCs or L929 cells (Fig. 1b).

\section{Effect of Britannin on cell cycle progression in NALM-6 cells}

NALM-6 cells were exposed to different concentrations of Britannin (1, 3 and, $5 \mu \mathrm{M})$ for $48 \mathrm{~h}$, and PI staining was used to evaluate the effect of the agent on the cell cycle progression. As shown in Fig. 3a, Britannin at the concentrations of 3 and $5 \mu \mathrm{M}$ increased the percentage of cells in the G1 phase while decreased the percentage of cells in the S phase, but did not affect the proportion of the cells in the G2 phase of the cell cycle as compared to the control group. Also, we used q-RT-PCR to investigate the effect of Britannin on the expression of p21 and p27, which are two genes that participated in the regulation of the cell cycle at the S phase. The results showed that at the time of $48 \mathrm{~h}$, the expression of these genes increased in a dose-dependent manner (Fig. 3b).

\section{Effect of Britannin on the induction of apoptosis in NALM-6 cells}

Annexin-V/PI staining and flow cytometry analysis was used to evaluate whether Britannin at the concentrations of 1,3 , and $5 \mu \mathrm{M}$ could induce apoptosis in NALM-6 cells. At the time of $48 \mathrm{~h}$, the results showed that Britannin increased the percentage of NALM-6 apoptotic cells from 2.33 at the control group to 4.2, 47.58 and, 82.1 at the concentrations of $1 \mu \mathrm{M}, 3 \mu \mathrm{M}$ and, $5 \mu \mathrm{M}$, respectively (Fig. 4a). To confirm the results of Annexin-V/PI staining and assure that the cell death was due to the induction of apoptosis, Hoechst33258 staining was used. If the induction of apoptotic cell death would be due to induction of apoptosis, then the nucleus of apoptotic cells would have appeared as irregular bright blue dots compared to the bluestained nucleus of normal cells. As presented in Fig. 4b, when NALM-6 cells were treated with Britannin, their nucleus stained irregularly, which is an indicator of induction of apoptotic cell death. Also, the increase in the 
expression of Bax (pro-apoptotic gene) and decrease in the expression of XIAP (anti-apoptotic gene) in NALM6 cells after exposure to increasing concentrations of Britannin was another evidence suggesting that this agent could induce apoptotic cell death in ALL-derived cell line (Fig. 4c).

\section{Britannin increased ROS levels in NALM-6 cells}

Several anti-cancer drugs could induce apoptotic cell death in cancer cells by increasing the production of Reactive Oxygen Specious (ROS) $[18,19]$. To evaluate whether Britannin-induced apoptosis is mediated through ROS production, NALM-6 cells were treated with different concentrations of the agent for $48 \mathrm{~h}$. As presented in (Fig. 4a), Britannin increased the ROS level in NALM-6 cells in a concentration-dependent manner. To ascertain that Britannin reduces the survival of NALM-6 cells by inducing ROS-mediated apoptotic cell death, we treated the cells with N-Acetyl-L-Cysteine (NAC), a well-known antioxidant and scavenger of ROS [20], either alone or in combination with Britannin. We found that when cells were exposed to NAC (80 $\mu \mathrm{m}$ ), the ability of Britannin to reduce the metabolic activity of the cells was diminished (Fig. 4b), suggesting that probably Britannin induced its cytotoxic effects on NALM-6 cells through the production of ROS.

\section{Effect of Britannin on the induction of autophagy in NALM-6 cells}

There is a compelling body of evidence reporting that some of the anti-cancer agents activate autophagy in cancer cells, but sometimes this happens in favor of the survival of cancer cells [21, 22]. The results showed that Britannin elevated the expression of Beclin1, Bnip3, Atg7 and, Atg10, genes involved in the regulation of autophagy in NALM-6 cells (Fig. 5a). The results of Acridine orange staining showed that while untreated control cells appeared in green fluorescence, Britannin-treated cells showed yellowish or reddish-green fluorescence, suggestive of the activation of autophagy in cells (Fig. 5b). To evaluate whether induction of autophagy due to Britannin was in favor of NALM-6 cells survival or oppose to it, we treated cells with Chloroquine (CQ) $(20 \mu \mathrm{M})$, which is an autophagy inhibitor [23]. The results of the MTT assay showed that inhibition of autophagy could increase the cytotoxic property of Britannin, as the metabolic activity of NALM-6 cells diminished more significantly when the cells were treated with Britannin and CQ (Fig. 5c). To confirm these results, we also performed Annexin-V/PI staining. As presented in Fig. 5d, flow cytometry results indicated the synergistic effect of concomitant treatment of Britannin and CQ on NALM-6 cells. While Britannin $(1 \mu \mathrm{M})$ and CQ $(20 \mu \mathrm{M})$ as a single agent increased the percentage of apoptotic cells to 4.2 and 6 , respectively, the combination of two agents induced apoptosis in $20.71 \%$ of the cells. 


\section{The synergistic effects of Britannin and VCR in NALM-6 cells}

First, in order to evaluate the optimum concentration of Vincristine (VCR) on NALM-6 cells, cells were treated with VCR (2-6 nM) for $48 \mathrm{~h}$. The results of the MTT assay showed that after $48 \mathrm{~h}$, the metabolic activity of the cells decreased by $39,54,68,81,90 \%$ at the concentrations of 2, 3, 4, 5, and $6 \mathrm{nM}$, respectively (Fig. 6a). Also, the results showed that the IC50 value for VCR in NALM-6 cells at $48 \mathrm{~h}$ is $5 \mathrm{nM}$. Given this, for synergistic experiments, we used VCR at the concentration of $3 \mathrm{nM}$. Then, NALM- 6 cells were treated simultaneously with lower concentrations of Britannin ( 1 and $2 \mu \mathrm{M})$ and VCR $(3 \mathrm{nM})$ for 48 and, the viability of the cells was evaluated using MTT assay. $48 \mathrm{~h}$ after treatment, the metabolic activity of the cells treated with the combination of Britannin and VCR decreased more significantly as compared to either agent alone (Fig. 6a), suggestive of the existence of synergistic effect between two agents. The CI and isobologram analysis results also revealed the existence of synergism between Britannin and VCR in NALM-6 cells (Fig. 6b \& Table 2). This finding was then confirmed by Annexin-V/PI staining. The flow cytometry results suggested the synergistic effect between Britannin and VCR, as the combination of two agents increased the percentage of apoptotic cells to $38.3 \%$. In contrast, the single-agent of Britannin $(1 \mu \mathrm{M})$ and VCR $(3 \mathrm{nM})$ were capable of inducing apoptosis in $7.7 \%$ and $16.2 \%$, respectively (Fig. 6c). 


\section{Discussion}

Acute Lymphoblastic Leukemia, a malignancy-affected lymphoid progenitor cell, more frequently occurs in children; however, a proportion of patients suffering from this malignancy are adults whose prognosis in most cases, is poor. Despite the improvements in the understanding of the disease and treatment approaches, the risk of disease relapse is still very high in these patients [24]. Some targeted therapies recently have been reached to clinical trials for the treatment of ALL, but even immunotherapies were not successful in preventing the risk of relapse and induction of resistance against chemotherapies [25]. Given these, still attempts for identification of new drugs for the treatment of ALL is continuing. In the present study, we found that Britannin, a Sesquiterpene Lactone derived from Inula aucheriana, a native plant of West Azerbaijan (Iran), exerted cytotoxic effects on different ALL-derived cell lines such as Nalm-6, REH, and JURKAT. In all cell lines, Britannin significantly reduced the survival of the cells and, among them, NALM- 6 with the IC50 values of $3.2 \mu \mathrm{M}$ shown to be the most sensitive ALL cell line to the agent.

Meanwhile, the same concentrations of Britannin had no cytotoxic effects on either normal PBMCs or L929 cells, suggestive of selective behavior of the drug against leukemic cells. Also, Britannin showed an ability to produce a synergistic effect with Vincristine (VCR), which is one of the chemotherapy drugs used in the treatment of ALL. When NALM-6 cells were treated with Britannin and VCR, the percentage of apoptosis induction increased more significantly by altering the expression of apoptotic-related genes, as compared to either agent alone. Given these results and based on the previous studies which suggested the cytotoxic activity of Britannin on different cancer cells such as breast cancer, liver cancer, and pancreatic cancer [10, 14], we aimed to evaluate the mechanism of action of agent in NALM- 6 cells.

In NALM-6 cells, we found that Britannin could induce G1 cell cycle arrest by increasing the expression of p21 and p27, two essential genes that inhibit the cell cycle in the S phase by inhibiting Cyclin D/CDK4 / 6 [26]. The negative effect of Britannin on the progression of the cell cycle was also reported in breast cancer cells which were mediated through Cyclin D1/CDK4-mediated pathway [27]. Another mechanism that was recruited by Britannin to reduce the survival of NALM-6 cells was an induction of apoptosis. Apoptosis that could be induced in cells through both intracellular and extracellular pathways is one of the significant mechanisms of cell death characterized by alteration in the structure of cell membrane and chromatin [28]. Our results showed that after treatment of NALM-6 cells with Britannin, while the expression of pro-apoptotic gene Bax increased, the expression of apoptotic inhibitor gene XIAP decreased. These changes in the balance of pro-apoptotic to anti-apoptotic genes subsequently led to the induction of apoptosis in NALM-6 cells. In agreement with our 
finding, Cui et al. also indicated that Britannin induced apoptosis in liver cancer cells by increasing AMPK expression, suppressing mTOR, and activation of Caspase-3 [17]. Also, there is some evidence showing that Britannine could reduce the expression of BCL-2 protein and increase the expression of Bax protein in breast cancer cells [29]. One of the best strategies that cytotoxic agents could induce cell death in cancer cells is to produce oxygen-containing entities. Although the production of the small amount of Reactive Oxygen Species (ROS) in the cells could be a help to the development of cancer, if its production surpasses the toxic threshold, ROS could induce apoptosis in cancer cells [30]. Many chemotherapy drugs induce cell death in cancer cells by potentiating the production of ROS [31, 32]. In our study, Britannin increased the production of ROS in NALM6 cells. Also, when NALM-6 cells were treated with N-Acetyl-L-Cysteine (NAC), a scavenger of ROS, we found that Britannin could induce neither apoptosis nor reduce the survival of the cells suggesting that the cytotoxic effects of Britannin are induced through ROS-dependent manner. In parallel to our study, other investigations on the cytotoxic effects of Britannin also revealed that the production of ROS is one of the mechanisms this drug recruited for induction of apoptotic cell death in cancer cells [17, 29].

Autophagy has a dual role in the regulation of cancer cell survival. While a group of studies has shown that activation of autophagy can favor cancer cells, especially under metabolic stress causes by anti-cancer stress [33], other studies indicated that activation of autophagy in cancer cells could induce apoptotic cell death [34]. Our results showed that Britannin exposure to NALM-6 cells activated autophagy, as revealed by Acridine orange staining and the expression of autophagy-related genes. However, when autophagy was inhibited by using Chloroquine (CQ), the sensitivity of NALM-6 cells to the anti-cancer effects of Britannin was potentiated. As an interpretation, it is reasonable to assume that the activation of autophagy in response to Britannin in NALM-6 cells is a compensatory mechanism through which malignant cells tried to maintain their survival. Although previous studies have reported the positive impact of Britannin on the activation of autophagy in cancer cells [17], no study has so far proposed that this mechanism could be a refractory response of cancer cells to this agent. Overall, our results showed that Britannin, a Sesquiterpene Lactone, had both anti-proliferative and cytotoxic effects against NALM-6 cells through inducing p21-mediated G1 cell cycle arrest and ROS-mediated apoptotic cell death. Furthermore, it also had no cytotoxic effects against normal cells. Given these, we proposed that Britannin could be a potent natural compound against leukemic cells; however, efforts are needed to understand better the molecular mechanisms of the agent and, more in vitro and in vivo experiments are required to check the safety of this agent as a monotherapy or in combination therapy. 


\section{Ethical approval}

This article does not contain any studies with human participants or animals performed by any of the authors.

\section{Conflicts of interest}

The authors declare that they have no conflict of interest.

\section{Funding detail}

This study was supported by a fund of Laboratory Hematology and Blood Bank Department, School of Allied Medical Science, Shahid Beheshti University of Medical Sciences, Tehran, Iran.

\section{Author's contributions}

Mohammadlou carried out the experiments and drafted the manuscript; Hamzeloo-Moghadam collected Inula aucheriana, prepared, isolated, and purified the compound; Mohammadi involved in supervised the project; Yami designed the primers; Gharehbaghian conceived of the study, designed and coordinated it, and finalized the manuscript. All authors gave final approval for publication.

\section{Acknowledgments}

The authors would like to express their gratitude to Shahid Beheshti University of Medical Sciences (Tehran, Iran) for supporting this study. 


\section{References}

1. Pui, C.H., K.E. Nichols, and J.J. Yang, Somatic and germline genomics in paediatric acute lymphoblastic leukaemia. Nat Rev Clin Oncol, 2019. 16(4): p. 227-240.

2. $\quad$ Pui, C.H., et al., Childhood Acute Lymphoblastic Leukemia: Progress Through Collaboration. J Clin Oncol, 2015. 33(27): p. 2938-48.

3. Terwilliger, T. and M. Abdul-Hay, Acute lymphoblastic leukemia: a comprehensive review and 2017 update. Blood cancer journal, 2017. 7(6): p. e577-e577.

4. Iacobucci, I. and C.G. Mullighan, Genetic Basis of Acute Lymphoblastic Leukemia. J Clin Oncol, 2017. 35(9): p. 975-983.

5. Pui, C.H., et al., Treating childhood acute lymphoblastic leukemia without cranial irradiation. N Engl J Med, 2009. 360(26): p. 2730-41.

6. $\quad$ Raetz, E.A., et al., Reinduction platform for children with first marrow relapse of acute lymphoblastic Leukemia: A Children's Oncology Group Study[corrected]. J Clin Oncol, 2008. 26(24): p. 3971-8.

7. Brower, V., Back to nature: extinction of medicinal plants threatens drug discovery. 2008, Oxford University Press.

8. Bahmani, F., et al., Centaurea albonitens extract enhances the therapeutic effects of Vincristine in leukemic cells by inducing apoptosis. Biomedicine \& Pharmacotherapy, 2018. 99: p. 598-607.

9. Yami, A., et al., Ergolide, a potent sesquiterpene lactone induces cell cycle arrest along with ROSdependent apoptosis and potentiates vincristine cytotoxicity in ALL cell lines. Journal of ethnopharmacology, 2020. 253: p. 112504.

10. Moghadam, M.H., et al., Anti-proliferative activity and apoptotic potential of britannin, a sesquiterpene lactone from Inula aucheriana. Natural product communications, 2012. 7(8): p. $1934578 X 1200700804$.

11. Chugunov, P., et al., The structure of britannin-a sesquiterpene lactone from Inula britannica. Chemistry of Natural Compounds, 1971. 7(3): p. 265-268.

12. Bown, D., The royal horticultural society. New encyclopedia of herbs and their uses. Dorling Kindersley Limited. 2002, Penguin Company, London.

13. Seca, A.M., et al., The genus Inula and their metabolites: from ethnopharmacological to medicinal uses. Journal of ethnopharmacology, 2014. 154(2): p. 286-310.

14. Moeinifard, M., et al., Britannin induces apoptosis through AKT-FOXO1 pathway in human pancreatic cancer cells. Biomedicine \& Pharmacotherapy, 2017. 94: p. 1101-1110.

15. Zhang, Y.F., et al., Britannin stabilizes $T$ cell activity and inhibits proliferation and angiogenesis by targeting PD-L1 via abrogation of the crosstalk between Myc and HIF-1 $\alpha$ in cancer. Phytomedicine, 2020. 81: p. 153425.

16. Fallahian, F., M. Hamzeloo-Moghadam, and M.H. Mahmoud Aghaei, Induction of apoptosis in human breast cancer cells by Britannin, a sesquiterpene lactone from Inula aucheriana. 2015.

17. Cui, Y.-Q., Y.-J. Liu, and F. Zhang, The suppressive effects of Britannin (Bri) on human liver cancer through inducing apoptosis and autophagy via AMPK activation regulated by ROS. Biochemical and biophysical research communications, 2018. 497(3): p. 916-923.

18. Wang, Q., et al., Luteolin induces apoptosis by ROS/ER stress and mitochondrial dysfunction in gliomablastoma. Cancer chemotherapy and pharmacology, 2017. 79(5): p. 1031-1041.

19. Mondal, J., A.K. Panigrahi, and A.R. Khuda-Bukhsh, Anticancer potential of Conium maculatum extract against cancer cells in vitro: Drug-DNA interaction and its ability to induce apoptosis through ROS generation. Pharmacognosy magazine, 2014. 10(Suppl 3): p. S524.

20. Koehn, F.E. and G.T. Carter, The evolving role of natural products in drug discovery. Nature reviews Drug discovery, 2005. 4(3): p. 206-220.

21. O'Donovan, T.R., G.C. O’Sullivan, and S.L. McKenna, Induction of autophagy by drug-resistant esophageal cancer cells promotes their survival and recovery following treatment with chemotherapeutics. Autophagy, 2011. 7(5): p. 509-524.

22. Fung, C., et al., Induction of autophagy during extracellular matrix detachment promotes cell survival. Molecular biology of the cell, 2008. 19(3): p. 797-806.

23. Fei, N., et al., Association of SMAD4 loss with response to neoadjuvant chemotherapy with the autophagy inhibitor hydroxychloroquine in patients with pancreatic adenocarcinoma. 2020, American Society of Clinical Oncology.

24. Waanders, E., et al., Mutational landscape and patterns of clonal evolution in relapsed pediatric acute lymphoblastic leukemia. Blood cancer discovery, 2020. 1(1): p. 96.

25. Nguyen, K., et al., Factors influencing survival after relapse from acute lymphoblastic leukemia: a Children's Oncology Group study. Leukemia, 2008. 22(12): p. 2142-2150. 
26. Coqueret, O., New roles for p21 and p27 cell-cycle inhibitors: a function for each cell compartment? Trends in cell biology, 2003. 13(2): p. 65-70.

27. Hamzeloo-Moghadam, M., et al., Anticancer activity of britannin through the downregulation of cyclin D1 and CDK4 in human breast cancer cells. Journal of cancer research and therapeutics, 2019. 15(5): p. 1105.

28. Tapon, N., et al., salvador Promotes both cell cycle exit and apoptosis in Drosophila and is mutated in human cancer cell lines. Cell, 2002. 110(4): p. 467-478.

29. Hamzeloo-Moghadam, M., et al., Britannin, a sesquiterpene lactone, inhibits proliferation and induces apoptosis through the mitochondrial signaling pathway in human breast cancer cells. Tumor Biology, 2015. 36(2): p. 1191-1198.

30. Khan, M., et al., Killing cancer with platycodin D through multiple mechanisms. Journal of cellular and molecular medicine, 2016. 20(3): p. 389-402.

31. Ruefli, A.A., et al., The histone deacetylase inhibitor and chemotherapeutic agent suberoylanilide hydroxamic acid (SAHA) induces a cell-death pathway characterized by cleavage of Bid and production of reactive oxygen species. Proceedings of the National Academy of Sciences, 2001. 98(19): p. 10833-10838.

32. Cho, H.-D., et al., Auriculasin-induced ROS causes prostate cancer cell death via induction of apoptosis. Food and Chemical Toxicology, 2018. 111: p. 660-669.

33. Chang, H. and Z. Zou, Targeting autophagy to overcome drug resistance: further developments. Journal of Hematology \& Oncology, 2020. 13(1): p. 1-18.

34. Rubinstein, A.D. and A. Kimchi, Life in the balance-a mechanistic view of the crosstalk between autophagy and apoptosis. Journal of cell science, 2012. 125(22): p. 5259-5268. 


\section{Figure legends}

Fig.1 The effect of Britannin on acute lymphoblastic cell lines. A and B) The results of MTT and trypan blue analysis revealed that while Britannin reduced the metabolic activity and the viability of leukemic cells, it had no cytotoxic effects on L929 and PBMCs. Values are given as mean \pm S.D. of three independent experiments. $* P \leq 0.05$ represented significant changes from the control

Fig. 2 The effects of Britannin on the progression of the cell cycle in NALM-6 cells. A and B) Britannin induced G1 cell cycle arrest in NALM-6 cells through up-regulating the expression of p21 and p27. Values are given as mean \pm S.D. of three independent experiments. $* P \leq 0.05$ represented significant changes from the control.

Fig. 3 The effects of Britannin on the induction of apoptotic cell death in NALM-6 cells. A) The results of Annexin-PI analysis revealed that Britannin significantly increased the apoptotic rate in NALM-6 cells, while it has no cytotoxic effects on normal PBMCs. B) The results of Hoechst33258 staining also indicated that the cytotoxic effects of Britannin on NALM-6 cells are mediated through induction of apoptosis. C) qRT-PCR analysis showed that the treatment of NALM-6 cells with Britannin resulted in downregulation of XIAP and upregulation of Bax. Values are given as mean \pm S.D. of three independent experiments. $* P \leq 0.05$ represented significant changes from the control.

Fig. 4 Britannin induced apoptosis in NALM-6 cells via accumulating ROS. A) After 48 h treatment of NALM-6 cells with Britannin, the intracellular levels of ROS augmented in the cells. B) NALM-6 cells were treated with NAC (to inhibit ROS generation) and Britannin. The results showed that in the presence of NAC, Britannin was unable to reduce the metabolic activity of NALM-6 cells, suggestive of the importance of ROS in Britannin-induced apoptotic cell death. Values are given as mean \pm S.D. of three independent experiments. ${ }^{*} P \leq$ 0.05 represented significant changes from the control.

Fig. 5 The effects of Britannin on autophagy in NALM-6 cells. A) Treatment of NALM-6 cells with Britannin resulted in the elevation in the expression of Bnip3, Beclin, Atg7 and, Atg10 genes. B) Acridine orange staining Britannin-treated NALM-6 cells appeared as yellowish or reddish-green cells, which indicated that this agent could activate autophagy in the leukemic cells. C and D) The inhibition of autophagy in NALM6 cells using CQ reduced the metabolic activity of leukemic cells. Moreover, MTT and Annexin-PI staining assays showed that when NALM-6 cells were treated simultaneously with CQ and Britannin, the cells' 
metabolic activity diminished more significantly compared to either agent alone. Values are given as mean \pm S.D. of three independent experiments. $* P \leq 0.05$ represented significant changes from the control.

Fig. 6 The synergistic effects of Britannin and vincristine (VCR). A and B) The MTT assay and CI calculation results indicated that Britannin could potentiate the sensitivity of NALM-6 cells to VCR, suggestive of the existence of synergism between both agents in ALL-derived NALM-6 cells. B) The results of Annexin-PI staining also indicated that the combination of Britannin and VCR increased the percentage of apoptotic cells more significantly than either agent alone. Values are given as mean \pm S.D. of three independent experiments. $* P \leq 0.05$ represented significant changes from the control. 
Table 1. Nucleotide sequences of the primers used for RT-PCR.

\begin{tabular}{|c|c|c|}
\hline Genes & Forward primer $\left(5^{\prime}-3^{\prime}\right)$ & Reverse primer $\left(5^{\prime}-3^{\prime}\right)$ \\
\hline Abl & CTT CTT GGT GCG TGA GAG TGA G & GAC GTA GAG CTT GCC ATC AGA AG \\
\hline $\mathbf{B A X}$ & CAT GGA GCT GCA GAG GAT GAT TG & CCA GTT GAA GTT GCC GTC AGA A \\
\hline p21 & CCT GTC ACT GTC TTG TAC CCT & GCG TTT GGA GTG GTA GAA ATC T \\
\hline XIAP & TGG CAA TAT GGA GAC TCA G & AGA ATT TGT AGA CTG CGT G \\
\hline p27 & AGC AAT GCG CAG GAA TAA GGA AGC & CAC AGA ACC GGC ATT TGG GGA ACC \\
\hline $\operatorname{Atg} 10$ & TGC AGG TGA GCT TCG TGT G & CTG GGC TGT GGT AAG TAA TGG AG \\
\hline $\operatorname{Atg} 7$ & ATT GCT GCA TCA AGA AAC CC & GAT GGA GAG CTC CTC AGC A \\
\hline BECLINE-1 & TGC AGG TGA GCT TCG TGT G & CTG GGC TGT GGT AAG TAA TGG AG \\
\hline Bnip3 & CCA CAA GAT ACC AAC AGA GCT T & CCG ACT TGA CCA ATC CCA TA \\
\hline
\end{tabular}

Table 2. Fa, Combination Index (CI) and Dose Reduction Index (DRI) for Drug Combination of Britannin with Vincristine.

\begin{tabular}{|cccccc|}
\hline \multicolumn{7}{c}{ Fa, CI \& DRI: BriVCR (Bri + VCR) } \\
\hline Dose Bri & Dose VCR & Fa & CI & DRI Bri & DRI VCR \\
1.0 & 3.0 & 0.56 & 0.72873 & 3.20285 & 2.40089 \\
2.0 & 3.0 & 0.7 & 0.72461 & 2.31371 & 3.41996 \\
\hline
\end{tabular}




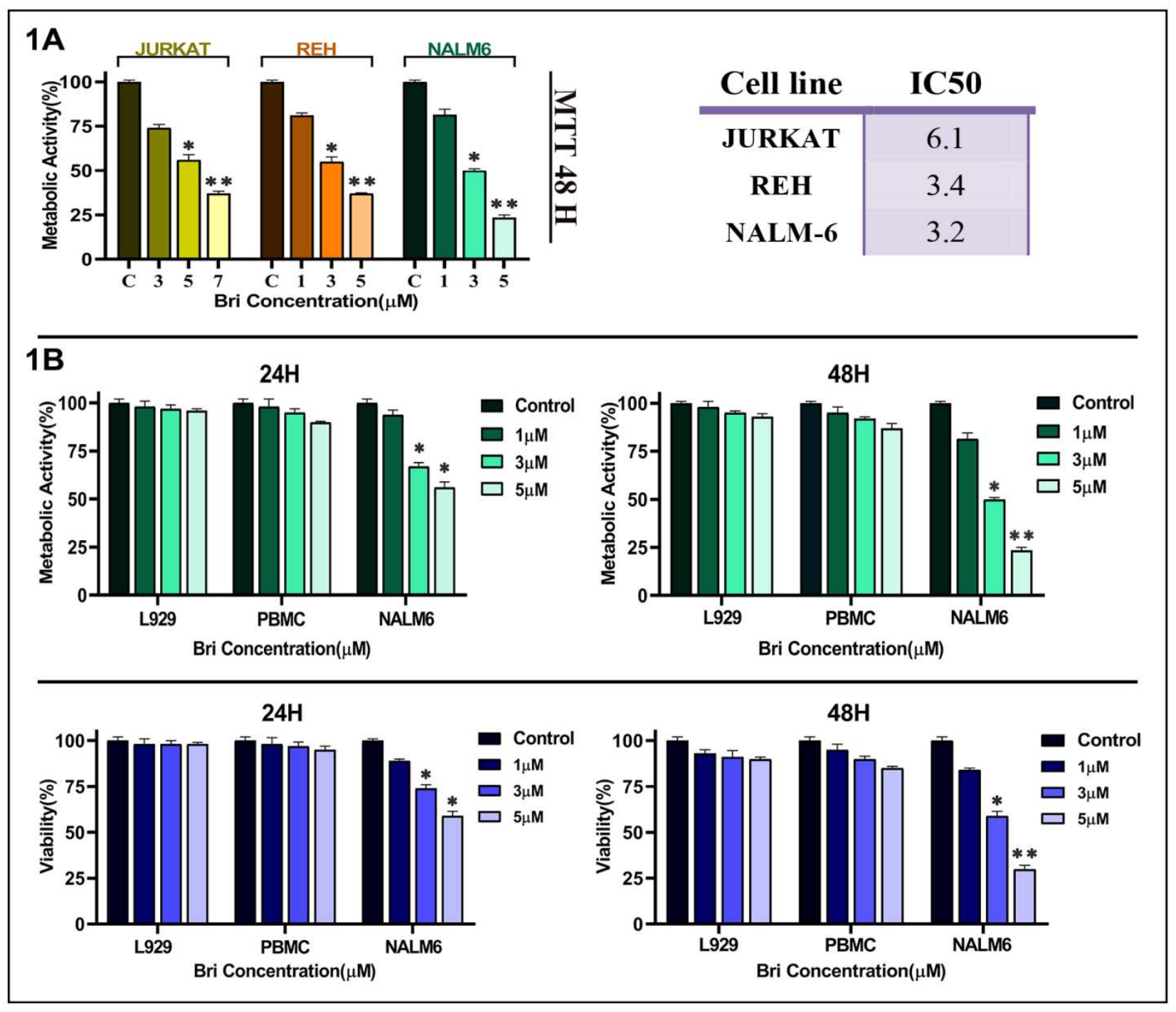




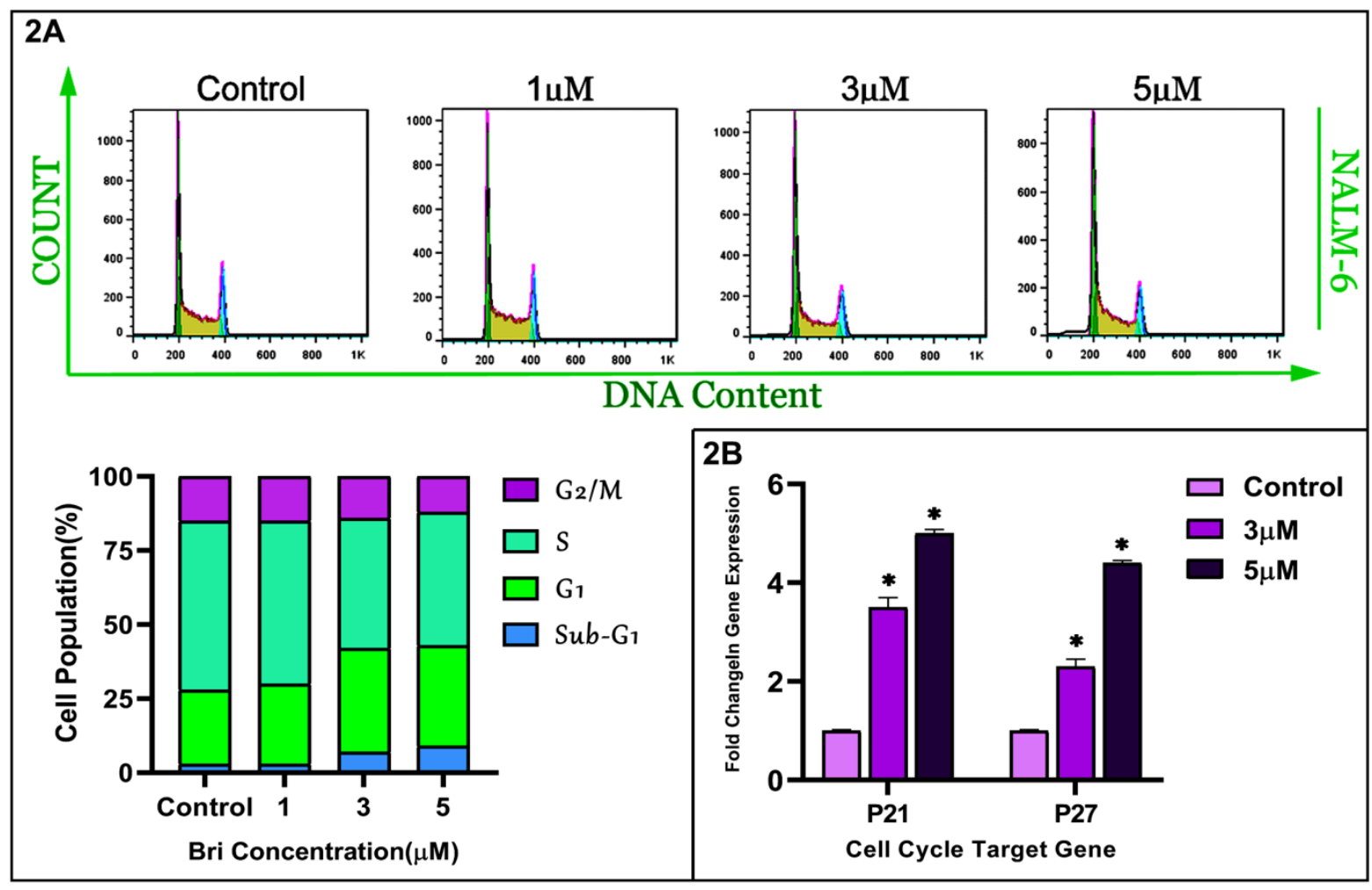




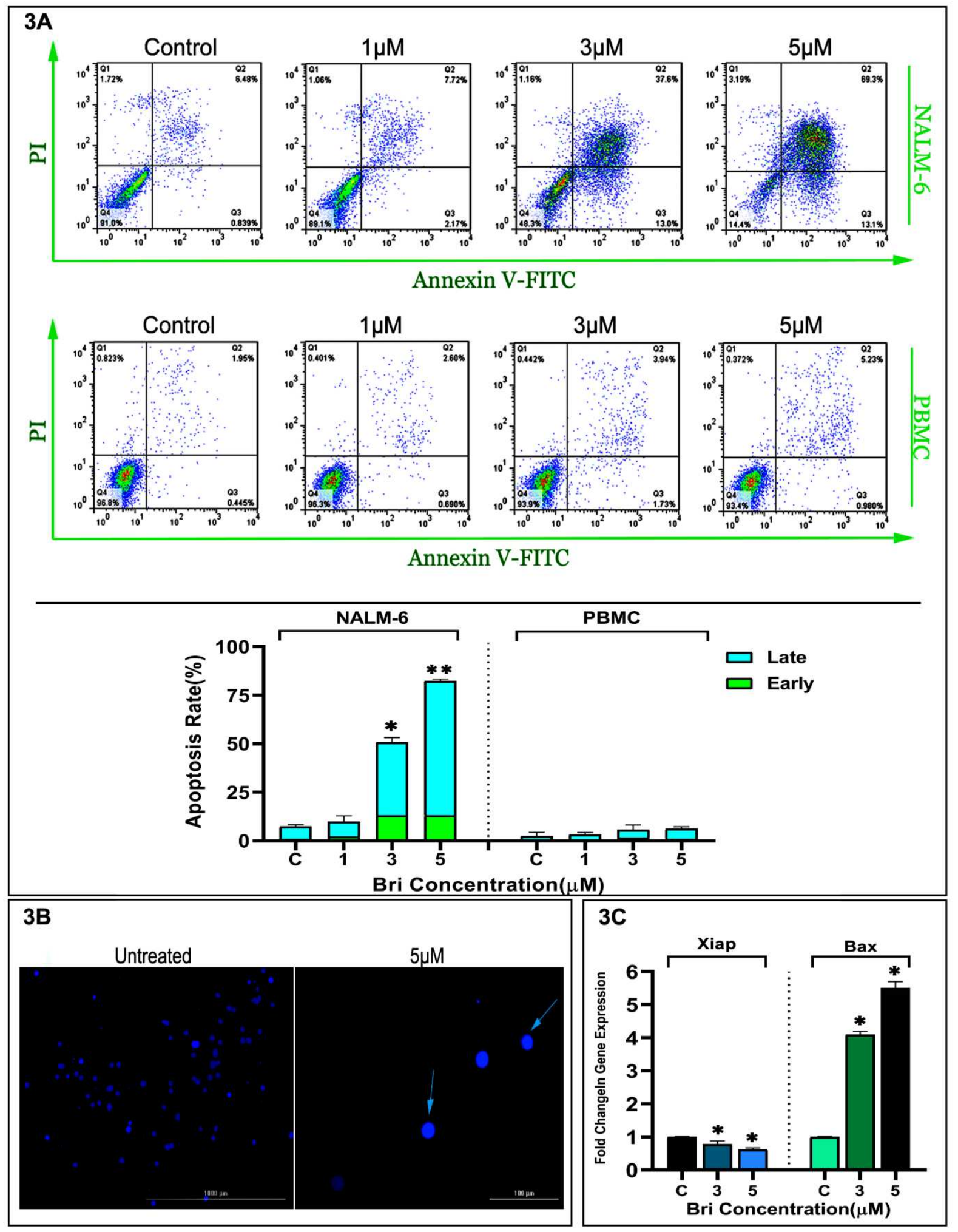



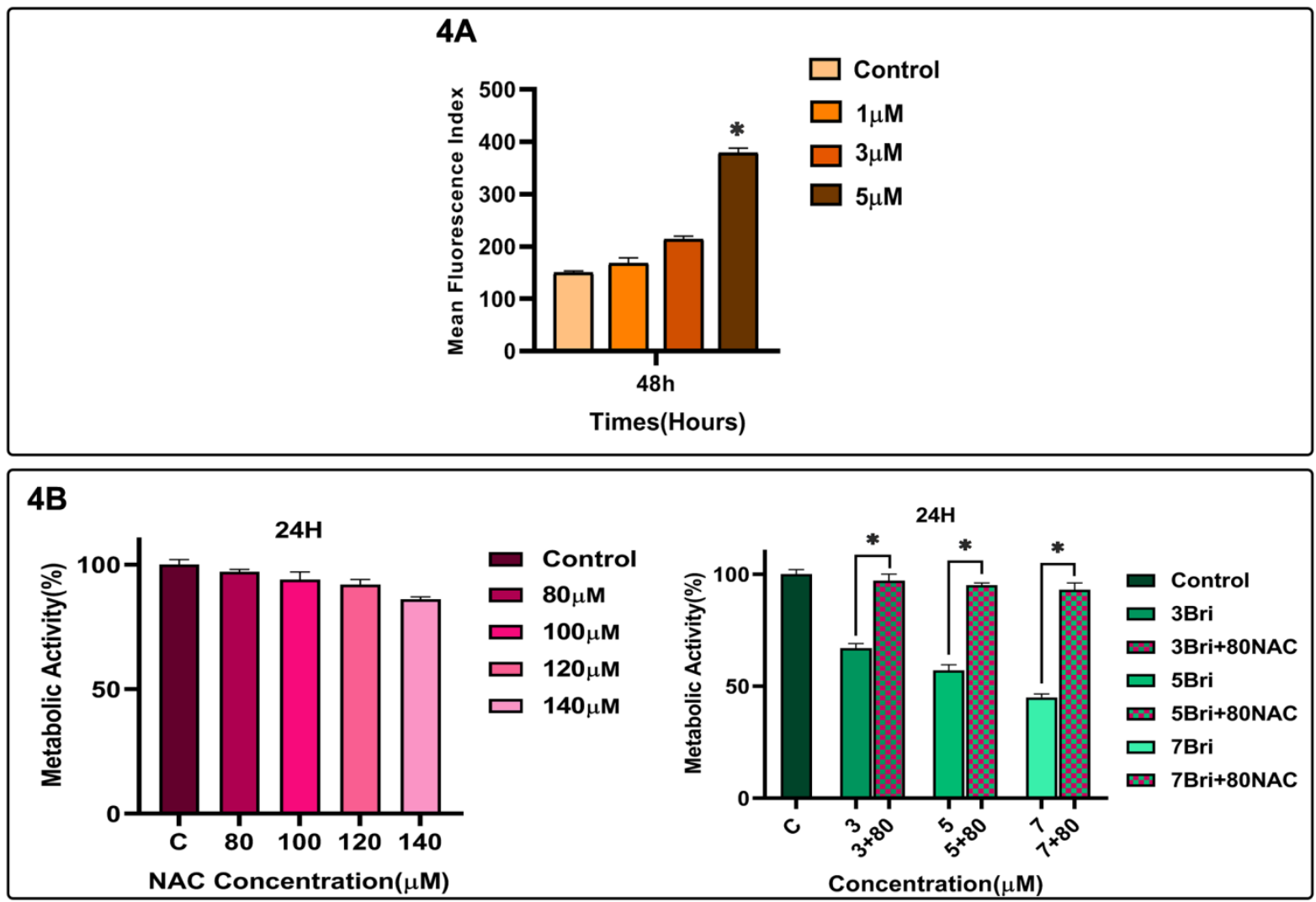
$5 A$

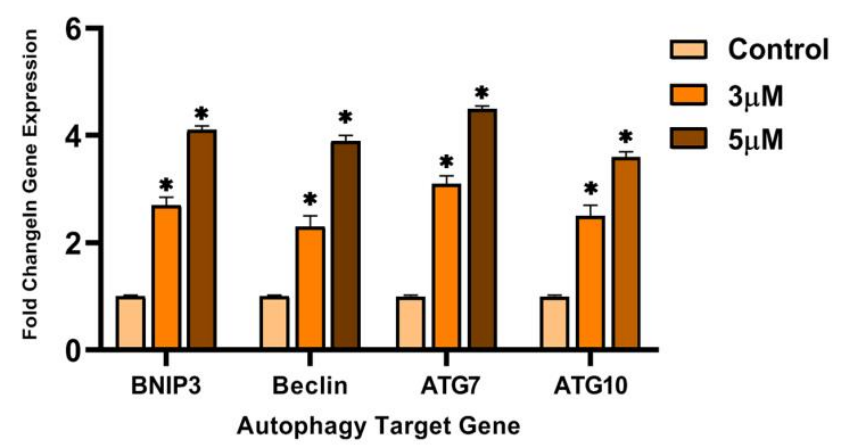

5B
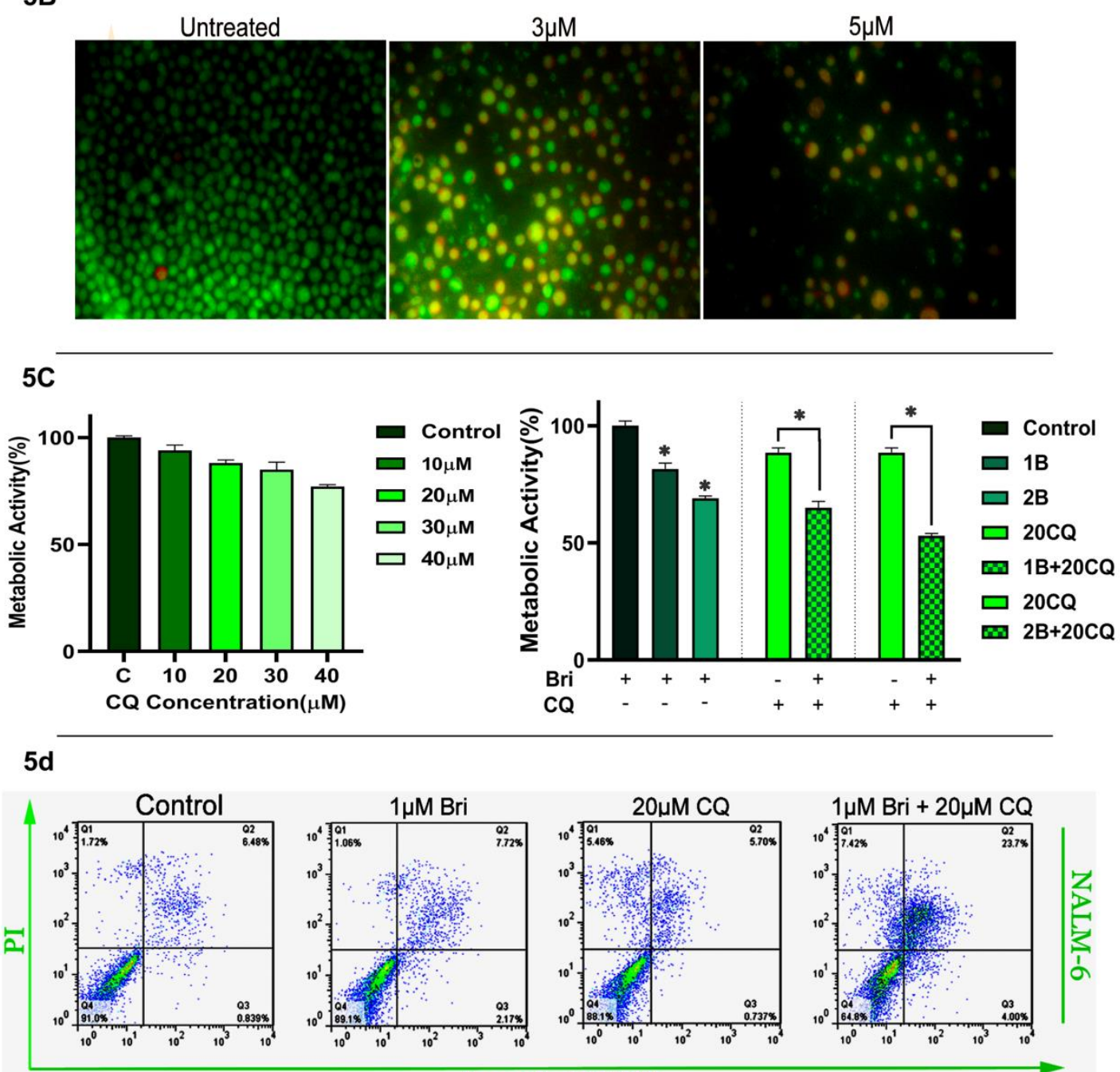

Annexin V-FITC

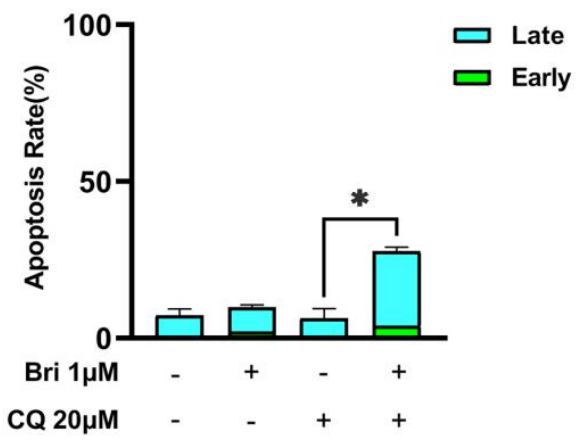




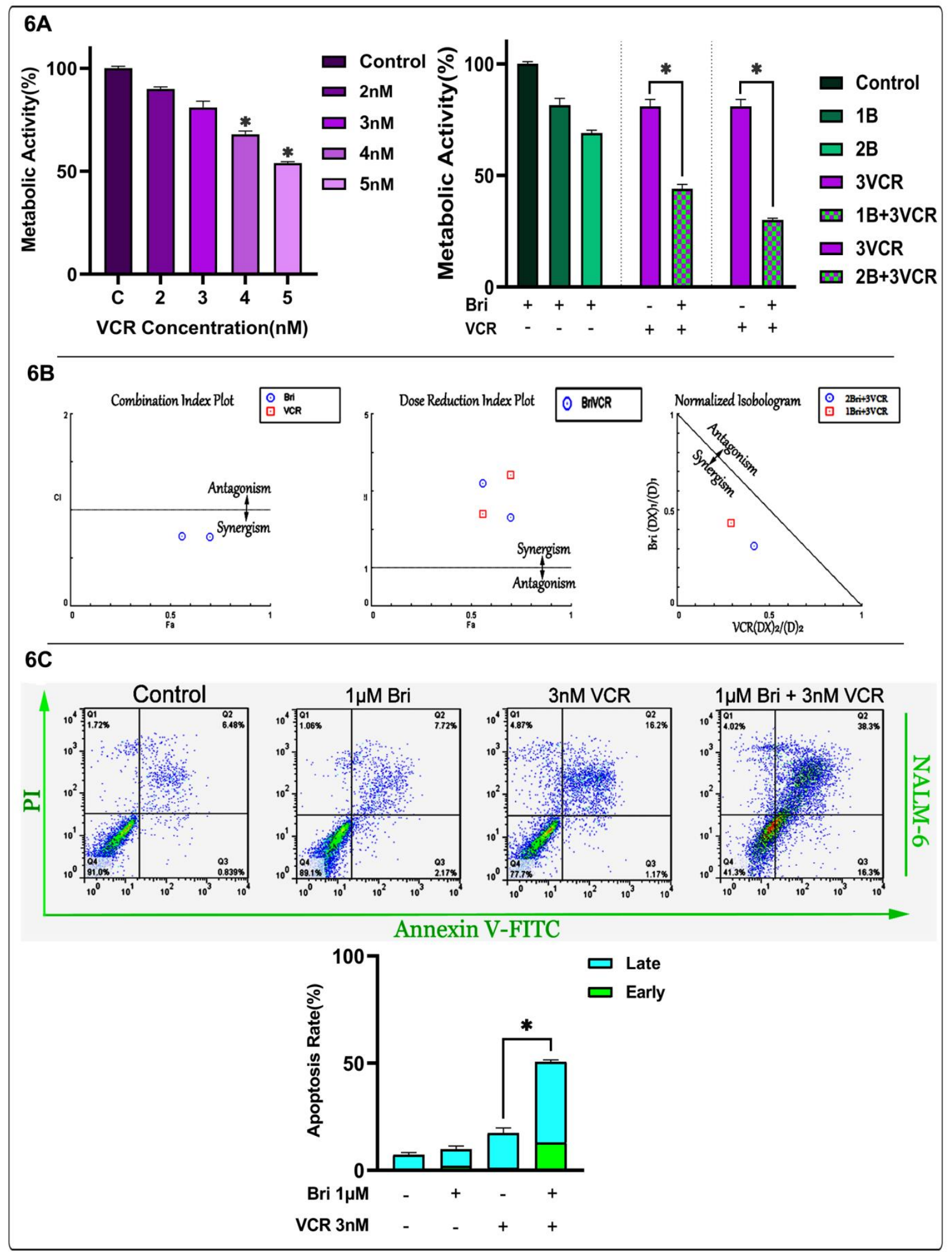


Figures

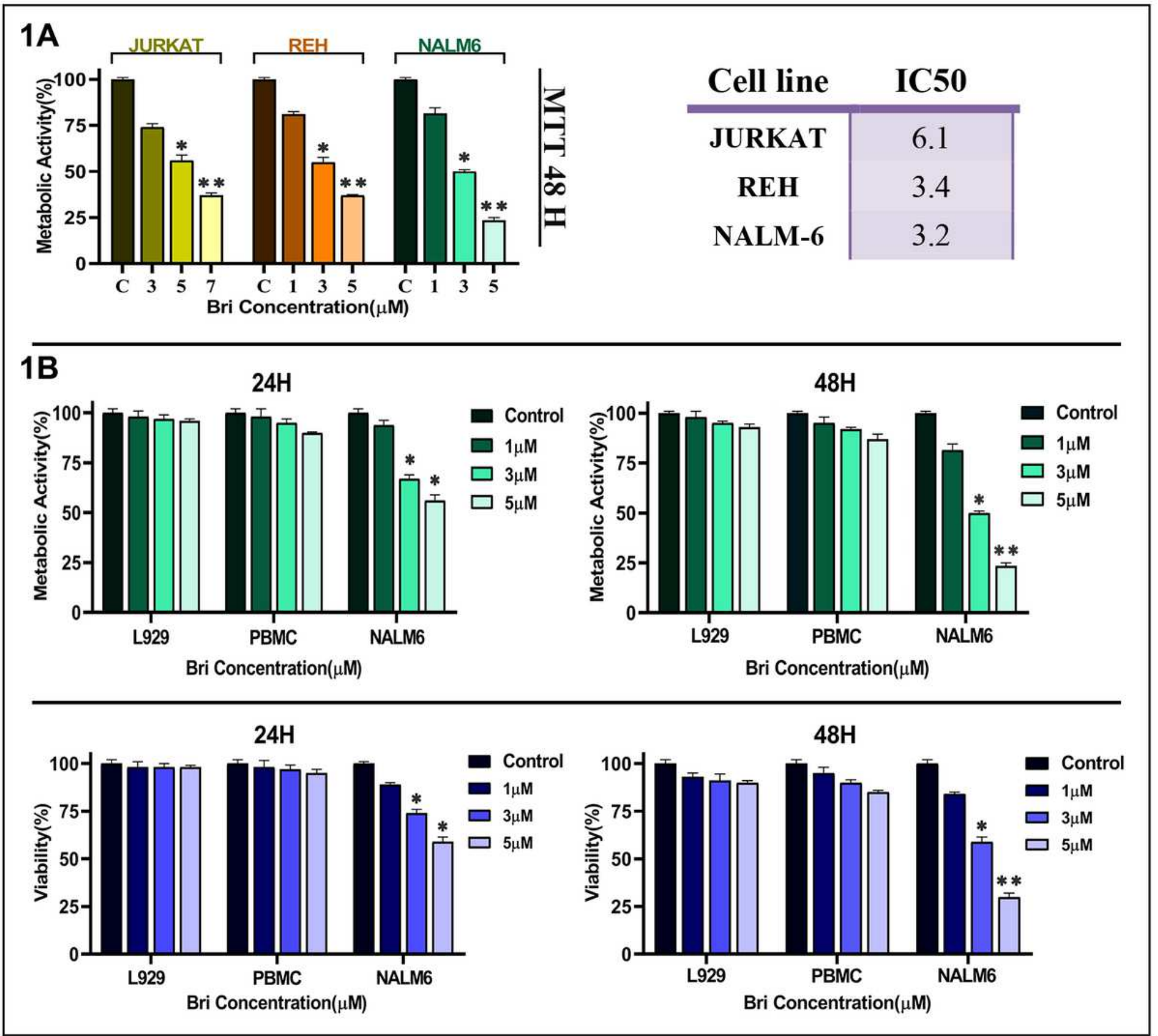

Figure 1

The effect of Britannin on acute lymphoblastic cell lines. A and B) The results of MTT and trypan blue analysis revealed that while Britannin reduced the metabolic activity and the viability of leukemic cells, it had no cytotoxic effects on L929 and PBMCs. Values are given as mean \pm S.D. of three independent experiments. ${ }^{*} \mathrm{P} \leq 0.05$ represented significant changes from the control 


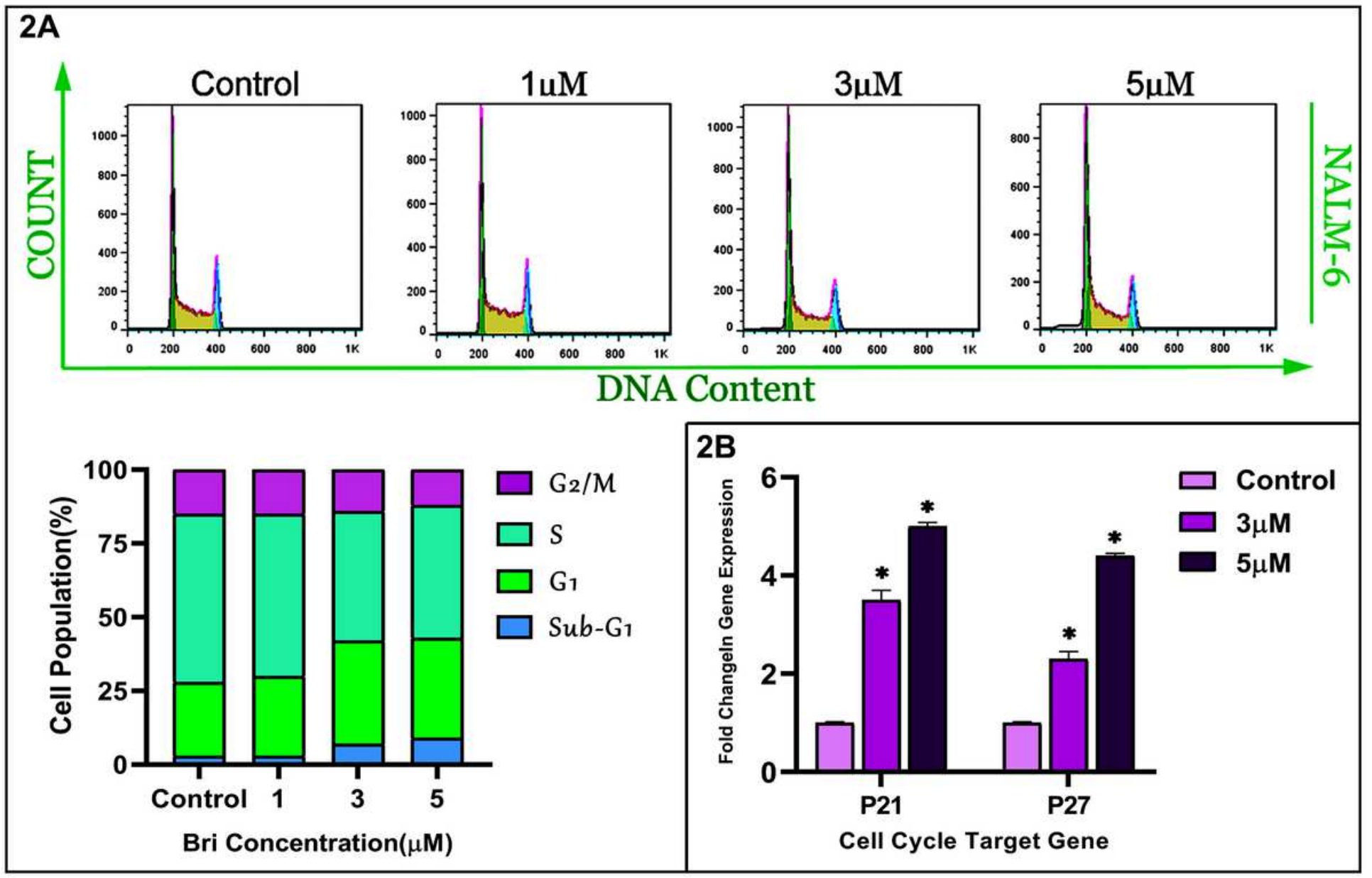

Figure 2

The effects of Britannin on the progression of the cell cycle in NALM- 6 cells. A and B) Britannin induced G1 cell cycle arrest in NALM- 6 cells through up-regulating the expression of p21 and p27. Values are given as mean \pm S.D. of three independent experiments. ${ }^{*} \mathrm{P} \leq 0.05$ represented significant changes from the control. 

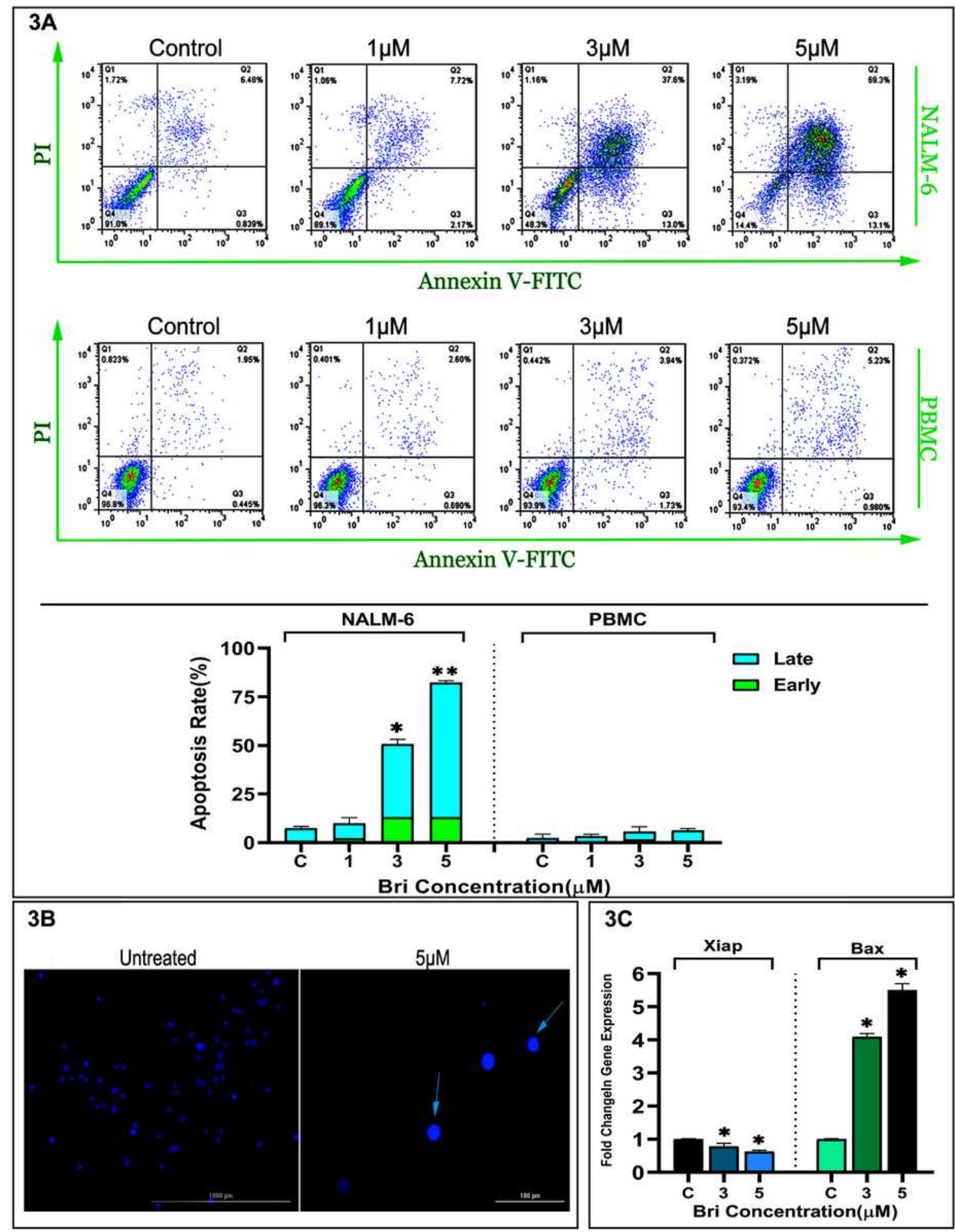

Figure 3

The effects of Britannin on the induction of apoptotic cell death in NALM- 6 cells. A) The results of Annexin-PI analysis revealed that Britannin significantly increased the apoptotic rate in NALM-6 cells, while it has no cytotoxic effects on normal PBMCs. B) The results of Hoechst33258 staining also indicated that the cytotoxic effects of Britannin on NALM- 6 cells are mediated through induction of apoptosis. C) qRT-PCR analysis showed that the treatment of NALM- 6 cells with Britannin resulted in 

experiments. ${ }^{*} \leq 0.05$ represented significant changes from the control.
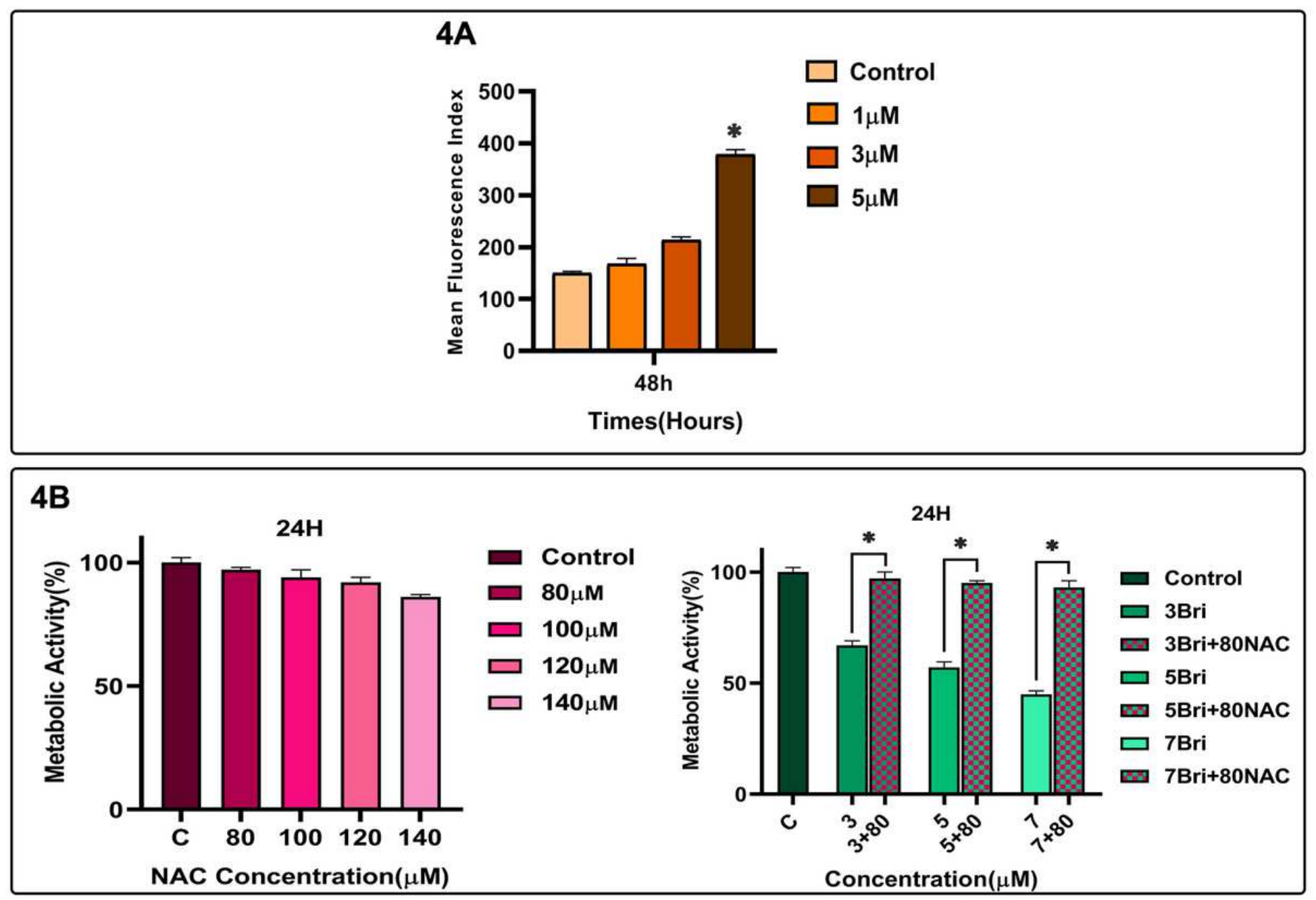

Figure 4

Britannin induced apoptosis in NALM- 6 cells via accumulating ROS. A) After $48 \mathrm{~h}$ treatment of NALM-6 cells with Britannin, the intracellular levels of ROS augmented in the cells. B) NALM- 6 cells were treated with NAC (to inhibit ROS generation) and Britannin. The results showed that in the presence of NAC, Britannin was unable to reduce the metabolic activity of NALM-6 cells, suggestive of the importance of ROS in Britannin-induced apoptotic cell death. Values are given as mean \pm S.D. of three independent experiments. ${ }^{*} \mathrm{P} \leq 0.05$ represented significant changes from the control. 
$5 \mathrm{~A}$

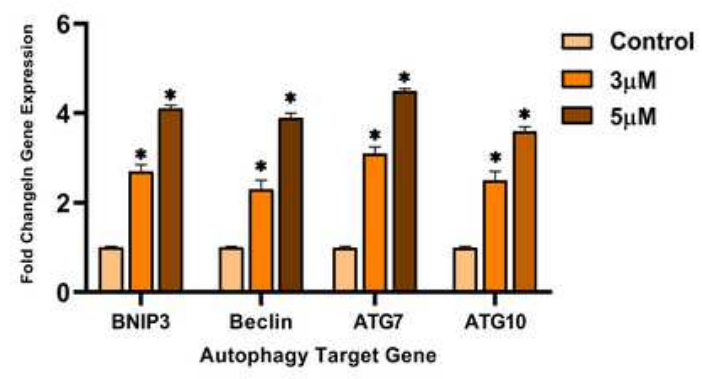

5B
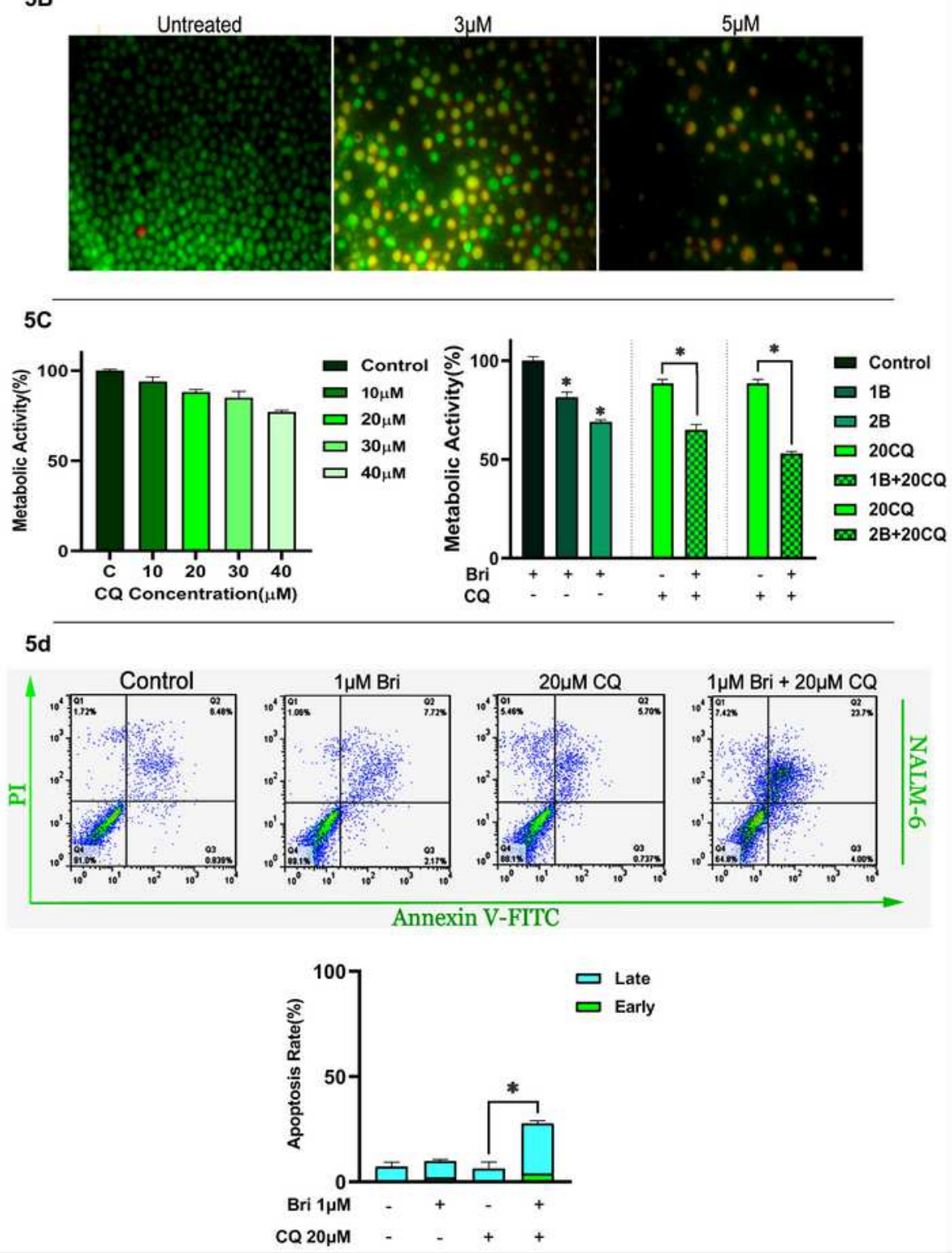

Figure 5

The effects of Britannin on autophagy in NALM- 6 cells. A) Treatment of NALM- 6 cells with Britannin resulted in the elevation in the expression of Bnip3, Beclin, Atg7 and, Atg10 genes. B) Acridine orange staining Britannin-treated NALM-6 cells appeared as yellowish or reddish-green cells, which indicated that this agent could activate autophagy in the leukemic cells. C and D) The inhibition of autophagy in NALM6 cells using CQ reduced the metabolic activity of leukemic cells. Moreover, MTT and Annexin-PI staining 
assays showed that when NALM- 6 cells were treated simultaneously with CQ and Britannin, the cells' metabolic activity diminished more significantly compared to either agent alone. Values are given as mean \pm S.D. of three independent experiments. ${ }^{*} \mathrm{P} \leq 0.05$ represented significant changes from the ontrol.

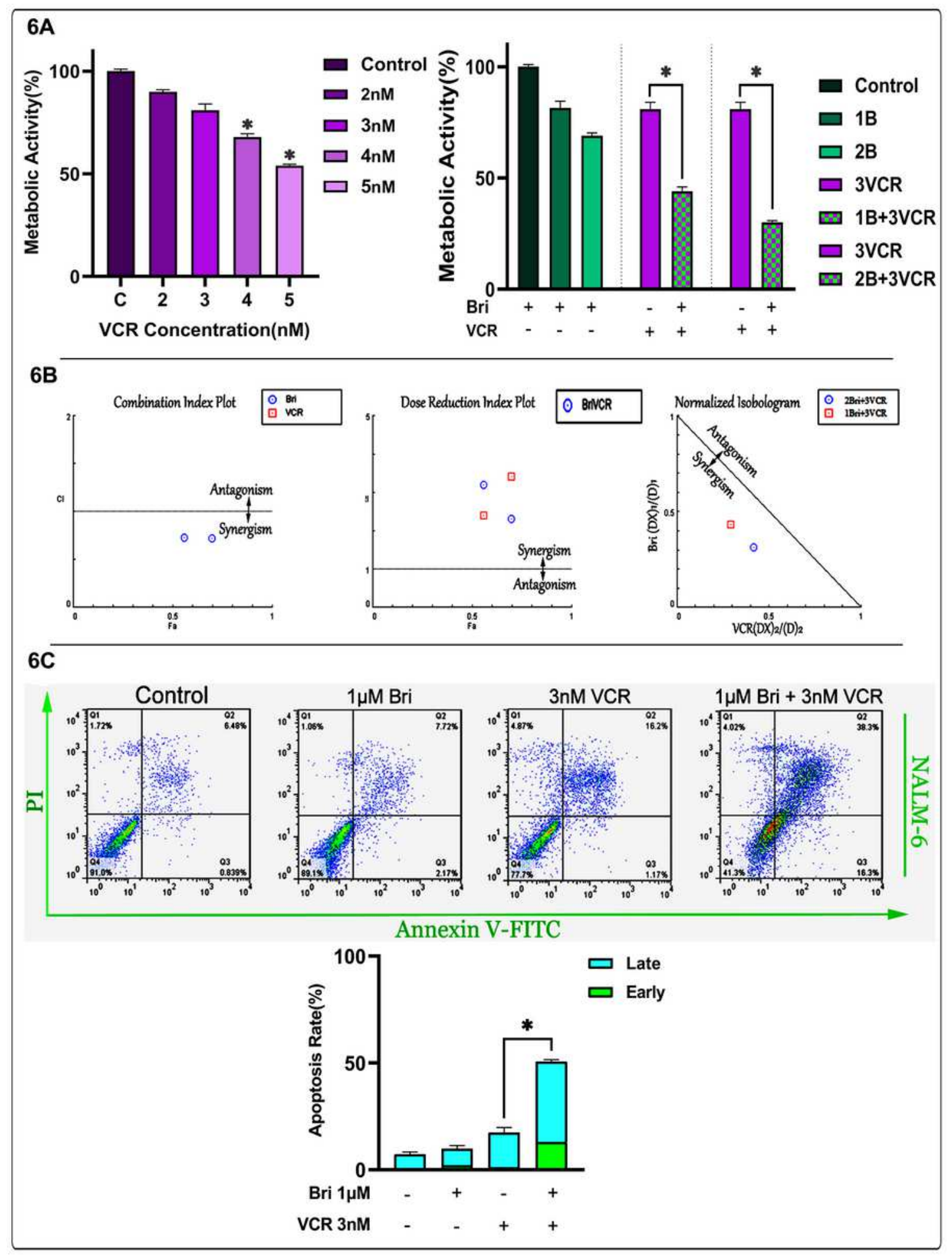

Figure 6

The synergistic effects of Britannin and vincristine (VCR). A and B) The MTT assay and Cl calculation results indicated that Britannin could potentiate the sensitivity of NALM- 6 cells to VCR, suggestive of the 
existence of synergism between both agents in ALL-derived NALM-6 cells. B) The results of Annexin-PI staining also indicated that the combination of Britannin and VCR increased the percentage of apoptotic cells more significantly than either agent alone. Values are given as mean \pm S.D. of three independent experiments. ${ }^{*} \mathrm{P} \leq 0.05$ represented significant changes from the control. 